\title{
“Anti-Metastatic Properties of Bio Synthesized Ag NPs on Osteosarcoma (MG-63) Cancer Cell Lines"
}

\author{
Qaysar Mohi Ud Din* and R Kanagaraj \\ Department of Biomedical Engineering, Bharath University, India
}

Received: September 08, 2017; Published: September 21, 2017

*Corresponding author: Qaysar Mohi Ud Din, Department of Biomedical Engineering, Bharath University, Chennai-73, Tamil Nadu, India; Email: qaysar007@yahoo.in

\begin{abstract}
Silver Nanoparticles have been synthesized by many techniques. Green synthesis of nano particle is a novel technique to synthesis nano particles by using plant sources. It is gaining attention because it is cost effective, eco-friendly and large scale production is possible. In this present study, Silver Nano particles are synthesized biologically by using plant extract. The silver nano particles synthesized are confirmed by their change of color to dark brown due to the phenomenon of surface Plasmon resonance. The Silver nano particles produced were characterized by UV-vis spectroscopy and Scanning Electron Microscopy (SEM). After the synthesis and characterization of silver Nano particles, the antimetastic properties of Ag Nano-particles were studied on Osteosarcoma cancer cell lines. The application of Ag Nano-particles to Osteosarcoma cancer cell lines produces anticancer activity and show good antimicrobial activity.
\end{abstract}

Keywords: Nano-particles; Antimetastatic; SPR; SEM

Abbreviations: Nano-particles; Antimetastatic; SPR; SEM

\section{Introduction}

Nanoparticles serve as the fundamental building blocks for many nanotechnology applications. Nanotechnology and nano structured materials play an ever increasing role in science, research and development as well as also in every day's life. Nanotechnology deals with materials with dimensions of nanometers, i.e. nano structured materials. In recent years, nanotechnology has induced great scientific advancement in the field of research and technology. Nanotechnology is the study and application of small object which can be used in all fields such as chemistry, biology, physics, material science and engineering. Nano-particle is a core particle which can perform as a whole unit in terms of transport and property. As the name indicates nano means a billionth or 10-9 unit. Its size range is usually from 1-100nm [1]. Nano size particles are quite unique in nature because nano size increase surface to volume ratio and also its physical, chemical and biological properties are different from bulk material.

\section{Green Synthesis of NP}

The production of nano-particles by living organisms or material of biological origin for example, nano-particles may be synthesized using living bacteria or fungi, or using plant extracts. That techniques provided an advantages over more traditional methods of synthesizing nano-particles because they are environmentally friendly, can take place around room temperature or lower, and require little intervention or input of energy [2]. In these methods, organisms involved are generally easily cultured in simple organic media, are a renewable resource, and can usually simply be left to do their work. Various organisms could synthesize in organic particles, including silica and calcium carbonate, or chalk, that has long been known. Many more micro-organisms are able to reduce metal ions to metal. Several bacteria can produce magnetic material by the reduction of iron compounds, incorporating magnetic nano-particles into bodies known as magnetosomes within their cells [3]. Some types of bacteria have been successfully employed in the biosynthesis of nano-particles. This can take place both intracellularly and extracellularly [4]. The primary requirement of green synthesis of AgNPs is silver metal ion solution and a reducing biological agent. In most of the cases reducing agents or other constituents present in the cells acts as stabilizing and capping agents, so there is no need of adding capping and stabilizing agents from outside [4]. The Ag+ ions are primary requirement for the synthesis of AgNPs which can be obtained from various water soluble salts of silver [5].

\section{Review of Literature}

The development of the concepts and experimental work is the broad category of nanotechnology. People have been preparing the glass windows with tiny colored metal particles especially silver which provide glassy yellow color. AgNps were synthesized by reduction of Silver Nitrate using fungus Trichoderma Viride. 
Aquous $\mathrm{Ag}(+)$ ions are reduced in solution when exposed to filtrate of T. Viride Extremely stable AgNPs produced. At $100 \mu \mathrm{g} /$ $\mathrm{mL}$ concentration, the silver nano-particles exhibited significant cytotoxic effects and the apoptotic features were confirmed through caspase-3 activation and DNA fragmentation assays [6]. Silver AgNPs were produced by reduction of Silver Nitrate by using aqueous of fresh aerial parts of Alternanthera Sessilie. AgNPs having spherical shape having size of $10-30 \mathrm{~nm}$. SPR band $420 \mathrm{~nm}$ in UV range [7]. The in-vitro cytotoxic effects of Silver AgNPs, increases the apoptosis rate of MCF-7 cell lines which increase with the concentration of silver nano-particles.

Nano particles were synthesized using Indigofera Longeracemosa. The cytotoxicity of the nano-particles was determined against SKMEL-28 cell line at different concentrations by MTT assay. UV visible spectrum indicated an absorption peak at $436 \mathrm{~nm}$. AgNPs were predominantly spherical and appeared in the size ranging from $30 \mathrm{~nm}$ to $110 \mathrm{~nm}$ as observed through SEM. Apoptotic cells were characterized by condensed and fragmented DNA. The expression of anti-apoptotic gene Bcl-2 decreased significantly and increased the expression of tumour suppressor gene p53 [8]. AgNPs were produced using Neem Compounds.The functionalization with Neem compounds as synthesis and capping agent showed very high anticancer activities against Gastric cancer cells in vitro [9].

Silver Nano-particles were produced by us uing aqueous silver nitrate as metal precursor and Artocarpus elasticus stem bark as both stabilizer and reductant. With the increase of reaction time in the room temperature, the size of the nanoparticles increased [10]. Jatrophacurcas, a tropical shrub plant was used for synthesizing nano-particles. This study showed that A549 lung cancer cell line proliferation was significantly inhibited at a dose dependent manner by AgNPs isolated from Jatropha species [11]. Silver nanoparticles of size 1-20 nm were produced by bioreduction of Ag+ ions using Aspergillus niger. The synthesized silver nanoparticles could efficiently inhibit various pathogenic organisms like bacteria and fungi [12].

Saliva officinalis extract was used to produce silver nanopaticles confirmed by colour change from yellow to brown and then characterized by UV-visible spectroscopy. The Hemoglobin content in the treated samples decreased which showed its inhibitory effect on angiogenesis [13]. They used plant extracts from Nelumba Lucifera,A.Indica and Boswellia Ovalifoliolata to synthesize Silver nanoparticles of size $425-435 \mathrm{~nm}$. The antmicroial activity was also studied with the zone o clearance produced by some pathogenic gram positive and gram negative bacteria [14]. Green and Sustainable chemistry. Silver nanoparticles were synthesized using pineapple (Ananas comosus juice). The synthesized nanoparticles showed optical absorption band peak at 430nm [15].

\section{Materials and Methods}

\section{Materials}

The materials which are used for the preparation of silver nanoparticles and the extract of tridax procumbens. Following are the materials which I used for this project,
i. Tridax procumbens(leaves)
ii. Beaker
iii. Conical flask
iv. Ethanol
v. Silver nano particles
vi. Aluminum foil
vii. Blotting paper
viii. Cotton
ix. Filter paper
x. Trisodium citrate
xi. Distilled water
xii. Stirrer

xiii. UV spectroscopy

xiv. Slide

xv. Coating equipment

xvi. SEM machine

\section{Selection of Plant for Biosynthesis of Silver Nanoparticles}

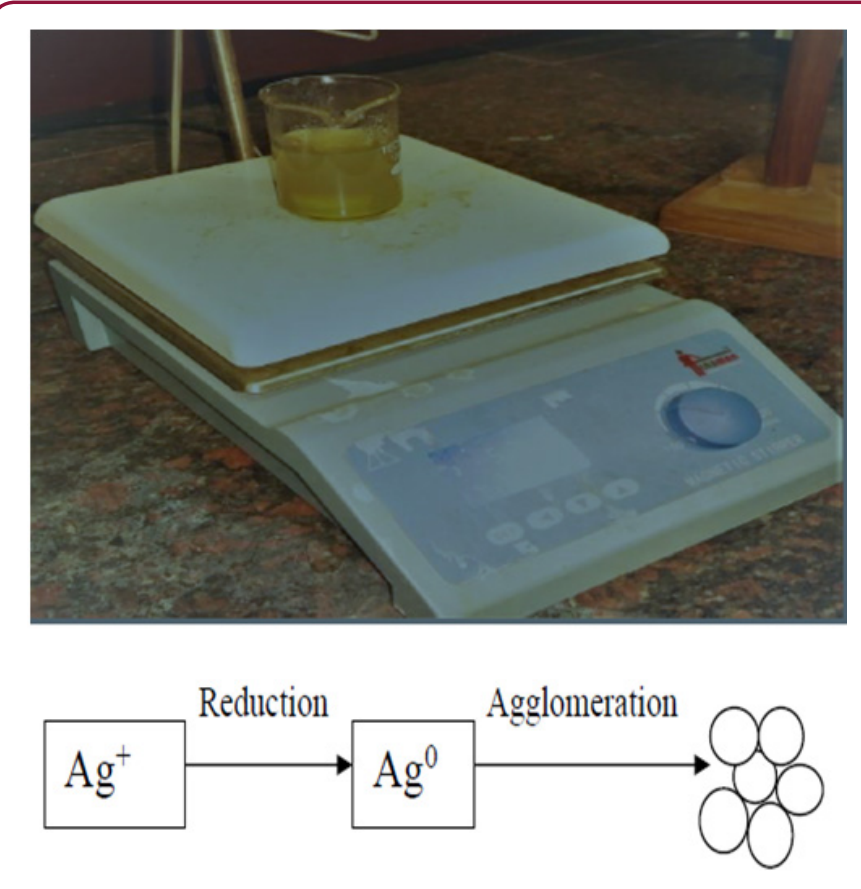

Figure 1: Synthesis of Nano particles.

The primary requirement for for the synthesis of AgNps is silver metal ion solution and a reducing biological agent. The plant extracts or the constituents present in cells acts as a stabilizing agent and capping agents. The Ag+ ions which are the primary requirement for the synthesis of AgNps can be obtained from various water soluble salts of silver. Silver nitrate solution was prepared in two beakers and both were marked. In one solution $10 \mathrm{ml}$ of sodium 
citrate was added as a reducing agent for the reduction of $\mathrm{Ag}+$ ions to Ag0. The solution was put on magnetic stirrer and incubated for one hour. The colour changed to yellow which showed the formation of silver nanoparticles (Figure 1). To another beaker $20 \mathrm{ml}$ of Tridax procumbens plant extract was added and continuously stirred and incubated for one hour. The colour change to yellow indicated the formation of silver nanoparticles. The Tridax procumbens plant extracts as a reducing agent. It also acts as a stabilizing agent as well as capping agent.

\section{Characterization of Silver Nanoparticles}

Preparation of samples for characterization: The glass slides were cut into desired sizes to coat the silver nano-particles. Diamond Glass cutter is used to cut the glass slides after which these are kept in Chromic acid and then cleaned with Acetone. Spectro-dip was used to dip coat the Silver nano-particles on glass substrate (Figure 2).

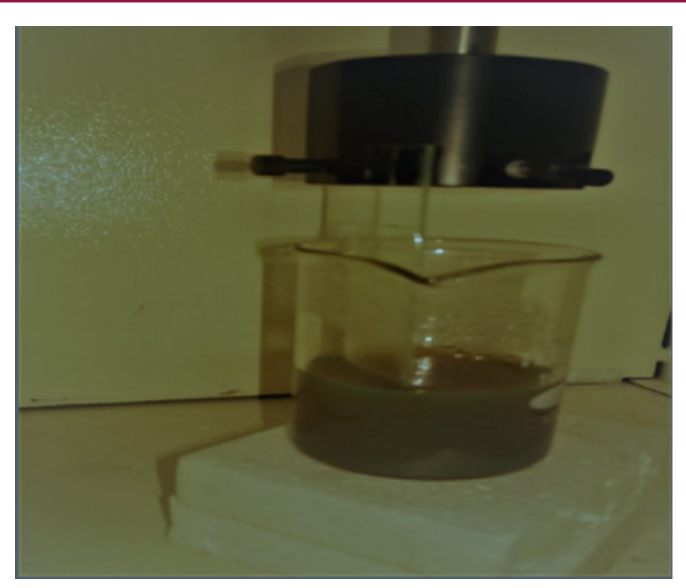

Figure 2: Dip coating.

\section{Results and Discussion}

The Ag NPs synthesized by biosynthesis are characterized by various techniques and after characterization their antimetastatic properties are studied on Cancer cell lines.

\section{Characterization of Silver Nano particles}

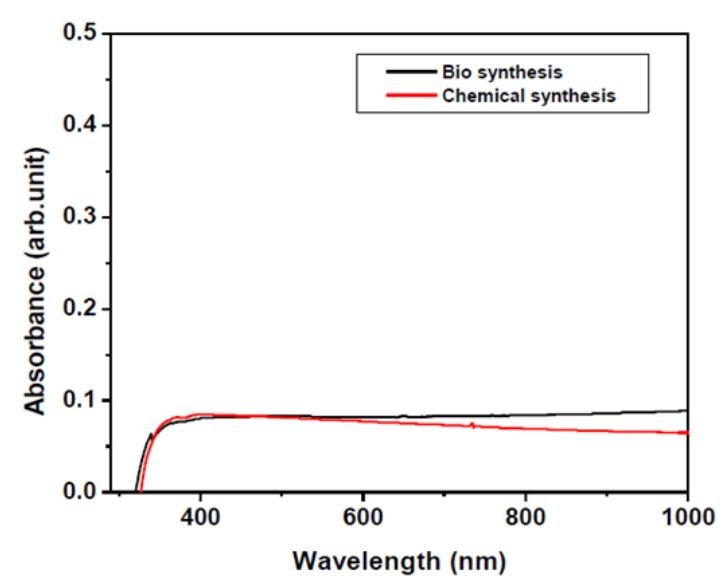

Figure 3: Spectrophotometric Analysis.

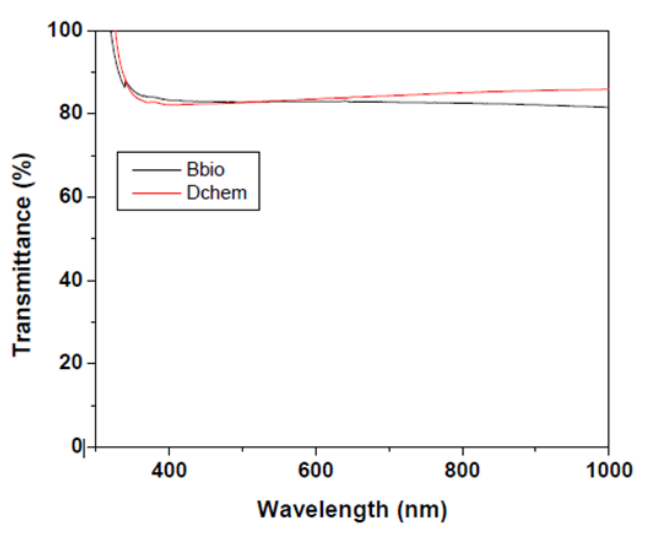

Figure 4: Spectrophotometric Analysis.

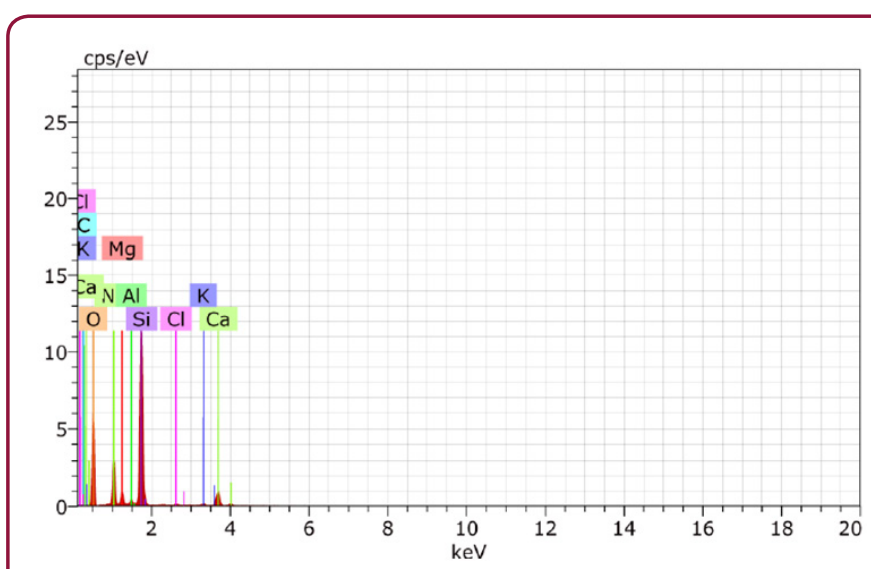

Figure 5: SEM analysis..

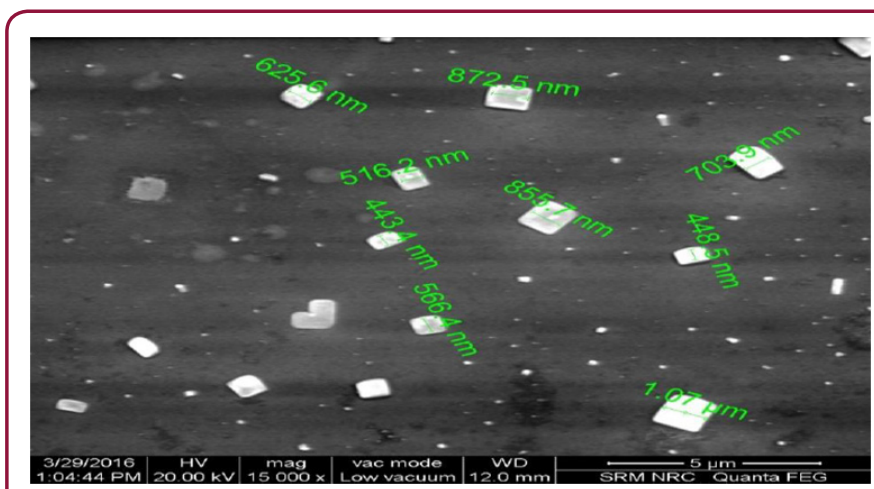

Figure 6: SEM Analysis.

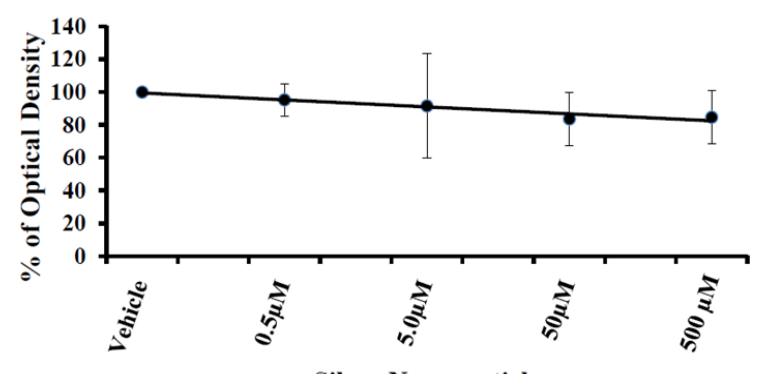

Silver Nanoparticle

Figure 7: Effect of AgNps on Osteosarcoma Cells. 
The characterization study of silver nano-particle is done by the examining size, shape and quantity of particles. A Number of techniques are used for this purpose, including UV visible spectroscopy, Scanning Electron Microscopy (SEM) (Figures 3-6). Effect of Silver nano-particles on Osteosarcoma (MG-63) Cell viability is shown. The silver nano-particles produced by using Tridax procumbens inhibited the growth of cancererous cells (Figures 7 \& 8).

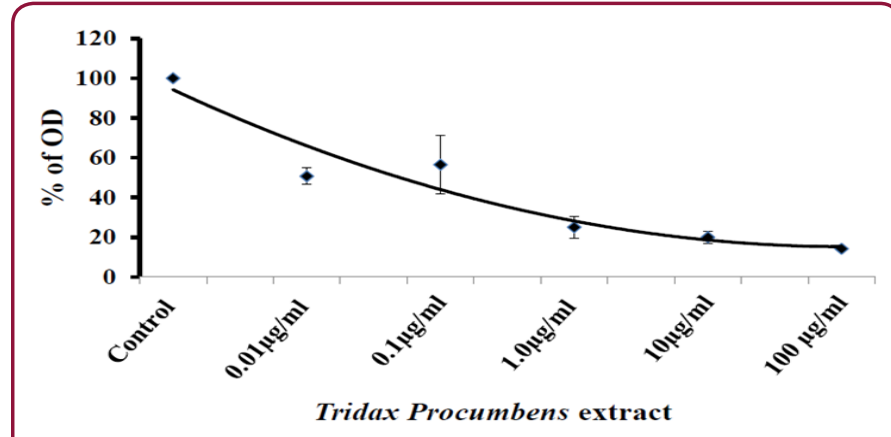

Figure 8: Effect of Tridax procumbens on Osteosarcoma Cell Viability.

\section{Conclusion \& Future Scope}

Silver nano-particles have been successfully produced by Tridax procumbens extracts which is economical and eco-friendly process. UV-Vis spectroscopy and SEM have confirmed the reduction of silver nitrate to silver nano-particles. The Ag NPs show significant anti metastatic effects on cancer cell lines. The use of nano-particles in cancer treatment is increasingly gaining interest and currently vast amount of research is being performed on the possible applications of nano-particles in medical field.

\section{References}

1. Mody VV, Siwale R, Singh A, Mody HR (2010) Introduction to Metallic Nano-particles. Journal of Pharmacy and Bioallied Sciences 2(4): 282289.

2. Sharma VK, Yangard RA, Lin Y (2009) Silver Nanoparticles: Green Synthesis and their antimicrobial Activities. Advances in Colloid and Interface Science 145: 83-96.
3. Grier N (1968) Silver and Its Compounds. Philadelphia, Pennsylvania, USA, pp. 375-398.

4. Ahmad A, Mukherjee P, Senapati S, Mandal D, Khan MI, et al. (2003) Extracellular biosynthesis of silver nanoparticles using the fungus Fusariumoxys porum Colloids and Surfaces. Bio interfaces 28(4): 313318.

5. Balaji Kulandaivelu, KM Gothandam (2016) Cytotoxic Effect on Cancer Cell Lines by Biologically Synthesized Silver Nano-particles" Braz Arch of Biol \& Tech 59.

6. Balaji Kulandaivelu, KM Gothandam (2016) Cytotoxic Effect on Cancer Cell Lines by Biologically Synthesized Silver Nano-particles" Braz Arch of Biol \& Tech 59 .

7. Jannathul Firdhouse, LalithaP (2015) Apoptotic efficacy of biogenic silver nano-particles on human breast cancer MCF-7 cell lines. Springer Open Choice 4: 113-121.

8. V Suseela, G lalitha (2016) Cytotoxic Efeect Of Green Synthesized Silver Nano particles On Skin Cancer SK MEL-28 Cell Lines. Intertational Journal Of Preclinical and Pharmaceautical Research 6(3): 118-125.

9. Sironmani T (2016) Therapeutic Potential of Neem Synthesized Silver Nano-particles on Human Gastric Cancer Cells in Vitro. World Journal of Nano Science and Technology 6(2): 90-110.

10. Abdullah NI, Ahmad MB, Shameli K (2015) Biosynthesis Of Silver Nanoparticles Using Artocarpus elasticus stem bark extract. Chemistry Central Journal 9: 61.

11. Nazeema H (2014) Synthesis and Characterization of Ag NPs Nano Particles From Two Medicinal Plants and Its Anti-Cancer Property.

12. Gaikwad Sagar, Bhosale Ashok (2015) Green synthesis of silver nanoparticles using Aspergillus niger and its efficacy against human pathogens. European Journal of experimenatal Biology 2(5): 1654-1658.

13. Baharara J, Namvar F, Mousavi M, Ramezani T, Mohamad R (2014) Anti angiogenesis effect of biogenic silver nanoparticles synthesized by saliva offcinalis in Chick chorioalantoic membrane(CAM). Molecules 19(9): 13498-13508.

14. G Geoprincy, S Ranganathan (2013) A review of Green synthesis of Silver nanoparticles. Asian Journal Of Pharmaceautical and Clinacal Research 6(1): 8-12.

15. Naheed Ahmad, Seema Sharma (2012) Green synthersis of silver nanoparticles using extracts of Ananas comosus. Green and Sustainable chemistry 2(4): 141-147.

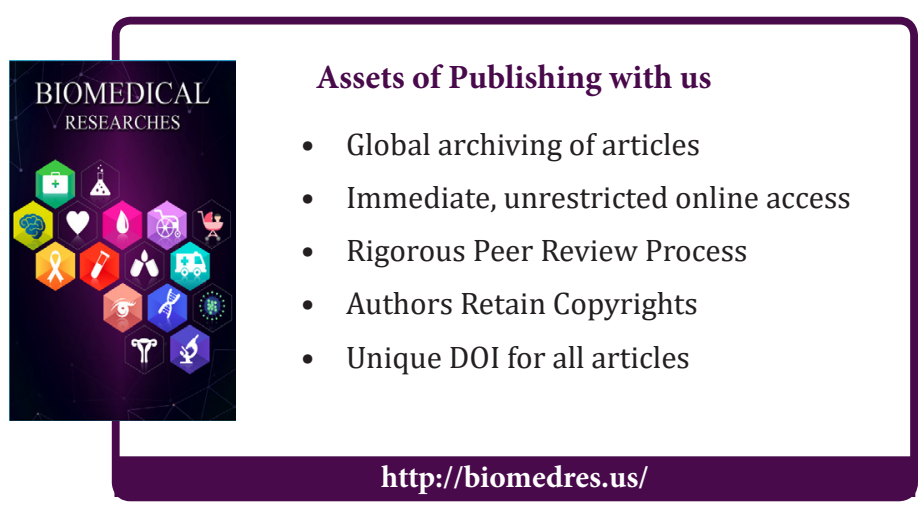

